Research Article

\title{
Prevention by the Natural Artocarpin of Morphological and Biochemical Alterations on UVB-Induced HaCaT Cells
}

\author{
Kunlathida Luangpraditkun $\left(\mathbb{D},{ }^{1}\right.$ Marion Tissot $\mathbb{D}^{\mathbb{D}},{ }^{2}$ Anupong Joompang $\mathbb{D},{ }^{3}$ \\ Pensri Charoensit $\mathbb{D}^{1},{ }^{1}$ François Grandmottet $\mathbb{D}^{\mathbb{D}},{ }^{4}$ Jarupa Viyoch $\mathbb{D}^{1},{ }^{1}$ and Céline Viennet $\mathbb{D}^{2}$ \\ ${ }^{1}$ Department of Pharmaceutical Technology, Faculty of Pharmaceutical Sciences and Center of Excellence for Innovation \\ in Chemistry, Naresuan University, Phitsanulok 65000, Thailand \\ ${ }^{2}$ UMR 1098 RIGHT INSERM EFS BFC, DImaCell Imaging Resource Center, University of Bourgogne Franche-Comté, \\ Besançon 25000, France \\ ${ }^{3}$ Department of Biochemistry, Faculty of Science, Khon Kaen University, Khon Kaen 40002, Thailand \\ ${ }^{4}$ Department of Biochemistry, Faculty of Medical Science, Naresuan University, Phitsanulok 65000, Thailand
}

Correspondence should be addressed to Jarupa Viyoch; jarupav@nu.ac.th and Céline Viennet; celine.viennet@univ-fcomte.fr

Received 17 April 2021; Revised 31 May 2021; Accepted 11 June 2021; Published 7 July 2021

Academic Editor: Alin Ciobica

Copyright (c) 2021 Kunlathida Luangpraditkun et al. This is an open access article distributed under the Creative Commons Attribution License, which permits unrestricted use, distribution, and reproduction in any medium, provided the original work is properly cited.

\begin{abstract}
Natural substances have gained considerable attention for skin protection against UV light reactions. Artocarpus altilis plant's heartwood extract is comprised of artocarpin as a major substance, already known for its interesting biological attributes as an antimicrobial, an anti-inflammatory, an antioxidant, and a melanogenesis inhibitor. The present work clarified the mechanism of natural artocarpin (NAR) with a purity of approximately 99\% against the effects of UVB-induced HaCaT keratinocyte apoptosis. The indicated results showed that NAR suppresses free radical production (ROS and nitrite) and apoptosis-related molecule activation (caspase-3, p-p53, p-p38, and NF- $\kappa$ B p65) and secretion (TNF- $\alpha$ ). Additionally, NAR prevented structural damages (nuclei condensation and fragmentation, apoptotic body formation, impaired cell adherence and round cell shape, disruption of F-actin filament, and clustering of cell death receptor CD95/Fas) and biophysical changes (plasma membrane rigidification). Thus, NAR acts directly from scavenging free radicals generated by UV and indirectly by suppressing morphological and biochemical UV-induced cell damages. Its biological effects are mainly attributed to antioxidant and antiapoptotic properties. Taken together, NAR could be considered as an effective natural product for photoprotective formulations.
\end{abstract}

\section{Introduction}

Keratinocytes (KCs) are the predominant cells in the epidermis, the outermost skin layer. An intact epidermis acts as an effective barrier that protects us from various environmental hazardous factors. Accordingly, the delicate balance between KC proliferation, differentiation, and apoptosis result in maintaining epidermal homeostasis [1-3]. KCs are important cellular targets for solar ultraviolet B (UVB) radiation that is responsible for sunburn, photoaging, immune suppression, and skin cancers [4-7]. At the cellular and molecular levels, excessive UVB exposure leads to several signaling responses involving morphological and biochemical changes on KCs [8]. Prominent events in KCs exposed to UVB are plasma membrane and DNA damages [2, 8-10]. The plasma membrane is a highly dynamic structure and is considered fluid, with rotational, translational, and transbilayer lipid movement. Its composition and organization contributes to cellular signaling and function. UV irradiation influences the membrane fluidity through the lipid environment [11]. It activates nitric oxide synthase to produce a molecule named nitric oxide (NO), and NO reduces membrane fluidity [12]. Furthermore, UVB evokes reactive oxygen species (ROS) reacting with polyunsaturated fatty acids which are essential components for the lipid membrane and inducing lipid peroxidation $[13,14]$. Lipid peroxidation leads to 
changes in the integrity, permeability, and fluidity of the plasma membrane [15]. It has been well documented that ROS mediate the phosphorylation of protein kinases (such as p-p38) all over the sequences of mitogen-activated protein kinase (MAPK) signal transduction cascades [16]. MAPKs act as the key upstream regulators for transcription factor activities, like the nuclear factor- $\kappa \mathrm{B}(\mathrm{NF}-\kappa \mathrm{B})$. UVB-provoked oxidative stress results in the stimulation of NF- $\kappa \mathrm{B}$ by p38/MAPK relating to cell death, matrix metalloprotease (MMPs) expression, and proinflammatory cytokine release including tumor necrosis factor-alpha (TNF- $\alpha$ ) $[17,18]$.

The direct UVB photon absorption by DNA or the indirect effect by oxidative stress via free radicals and ROS brings about DNA damages (cyclobutane pyrimidine dimers (CPD) and 6-4 photoproducts (6-4 PP)). They activate, via the MAPK signaling pathway, the nuclear phosphoprotein p53 which controls cell cycle arrest and DNA repair or induces the unpaired cells to undergo apoptosis $[4,19,20]$. UVB is a proapoptotic agent through the stimulation of interrelating signaling cascades involving the activation of cysteine proteases named caspases. Caspase- 3 is the most important terminal caspase essential for a series of morphological changes and execution of apoptosis [21]. Caspase activation is initiated through two major apoptotic mechanisms, the intrinsic pathway depending on the DNA damage and the activated p53 and the extrinsic pathway that occurs by the activation of the TNF family (TNF-R1, CD95 (Fas/APO-1), or TRAIL-R which are death receptors located on the cell membrane) $[2,19,20,22]$. It has been reported that the clustering of these surface receptors can be induced by UVB, even without ligand pairing anymore [22-25].

Nowadays, many natural plant-extracted compounds are used as photoprotective agents against UV-induced skin disorders. Several reports have shown interest in flavonoids in the prevention of diseases due to their pharmacological actions, mainly their antioxidant and chelating properties [26]. Notably, it has been shown that the Artocarpus altilis plant possesses biological efficacy, and in vitro as well as in vivo research is focused on antioxidation [27-33], antilipid peroxidation [30,33], anti-inflammation [30, 32], antityrosinase activity [27-29], and antiapoptotic [33] activity. Our previous data have demonstrated the photoprotection activities of the natural artocarpin (NAR) isolated from Artocarpus altilis's heartwood extract in UVB-induced keratinocyte apoptosis [33]. We showed that pretreatment with NAR attenuates oxidative stress by acting as free radical scavengers-both ROS and RNS (reactive nitrogen species) were scavenged-protecting DNA, and modulating the cell cycle. In this present work, to further define the antiphotodamaging mechanism of NAR, we investigated the morphological and biochemical effectiveness of the extract on UVBaffected human $\mathrm{HaCaT}$ keratinocytes. We studied oxidative stress (ROS and nitric oxide (NO)), biophysical change in the plasma membrane (membrane fluidity), cell structural features (actin cytoskeleton, CD95 membrane death receptor), and expression of apoptosis-related molecules (caspase-3, TNF- $\alpha$, p53, p38/MAPK, and NF- $\kappa$ B). Our results showed that NAR interacts with the plasma membrane, absorbs UVB rays, and decreases UV-mediated oxidative stress, thereby modulating different signaling cascades leading to apoptosis. These findings provided significant information about the potential usefulness of NAR for UV protection against skin damages together with the prophylactic actions to restore the epidermal skin barrier function.

\section{Materials and Methods}

2.1. Purification of Natural Artocarpin. Natural artocarpin was purified from the heartwood of the A. altilis plant according to the method described in previously published papers [32, 33]. Briefly, the heartwood was chipped into small pieces and dried at $45^{\circ} \mathrm{C}$ until dryness. The dried heartwood was macerated with diethyl ether at room temperature for 2 cycles ( 2 days/cycle). The gathered extract was filtered, and the solvent was removed by using a rotary evaporator. The artocarpin was purified by using column chromatography. The silica gel (No. 60, Merck, Darmstadt, Germany) was packed into a column. Then, the column was eluted with an eluting solvent of hexane and a continuously increasing ratio of ethyl acetate. Every $5 \mathrm{~cm}^{3}$ of fractions was collected, and the remaining flavonoid was assessed using thin layer chromatography (TLC) (Merck, Darmstadt, Germany). Only similar TLC profiles were gathered, and the solvent was removed. The concentrated extract was stored at $4^{\circ} \mathrm{C}$. All solvents were of analytical grade and purchased from Labscan Asia Co., Ltd., Thailand.

2.2. Determination of the Purity of the Natural Artocarpin. The content of artocarpin in the extract was determined using isocratic high-performance liquid chromatography (HPLC). The system consisted of an SPD-20A UV detector, an LC-20AP pump (Shimadzu Co., Ltd., Kyoto, Japan), and a column (with a diameter of $250 \times 4.60 \mathrm{~mm}$ ) packed with $5 \mu \mathrm{m} \mathrm{C18} \mathrm{(Phenomenex} \mathrm{Gemini} \mathrm{column).} \mathrm{Methanol} \mathrm{and}$ water $(80: 20)$ were used as the mobile phase. Natural artocarpin was dissolved in this mobile phase. The sample was injected into column with a volume of $20 \mu \mathrm{L}$. The isocratic mode was performed with a flow rate of $1 \mathrm{~mL} / \mathrm{min}$ and monitoring at $282 \mathrm{~nm}$. A calibration curve of the integrated peak area generated from standard artocarpin (BioBioPha Co., Ltd., Yunnan, China) was used to calculate the quantity of artocarpin. All mobile phases were of HPLC grade. All experiments were performed in triplicate $(n=3)$.

2.3. HaCaT Cell Culture. HaCaT cells were purchased from CliniSciences (France). They were cultured in Dulbecco's Modified Eagle's Medium supplemented with $10 \%$ fetal bovine serum, 10,000 U/mL penicillin, and $10 \mathrm{mg} / \mathrm{mL}$ streptomycin (all from PAN Biotech, Dominique Dutscher, France) at $37^{\circ} \mathrm{C}$ in a humid atmosphere containing $5 \%$ $\mathrm{CO}_{2}$. When cells (from passages 3 to 22 ) reached $70-80 \%$ confluence, they were trypsinized, planted at different densities according to the parameters studied, and incubated for $24 \mathrm{hr}$.

2.4. Pretreatment of HaCaT Cells with Natural Artocarpin (NAR). NAR was isolated from fresh heartwood of the Artocarpus altilis plant as previously described [33]. HaCaT cells were pretreated for $24 \mathrm{hr}$ with nonsupplemented medium, 
and NAR was then added $(3.1 \mu \mathrm{g} / \mathrm{mL})$. NAR was dissolved in noncytotoxic DMSO concentration $(<0.1 \% v / v$ as previously described).

2.5. UVB Exposure. Cells were exposed to UVB irradiation with an intensity of $55 \mathrm{~mJ} / \mathrm{cm}^{2}$, as previously described [33]. The UV source was provided by UVB tubes $(8 \mathrm{~W}$, F8T5, Sankyo Denki, Japan) which radiate UV rays during $280-360 \mathrm{~nm}$ (peak wavelength from 305 to $315 \mathrm{~nm}$ ). The UVB dose was determined using UV light meter (IL1700, International Light Technologies, USA). Before irradiation, the phosphate-buffered saline (PBS) was used to rinse cells for 2 times, and they were then exposed to UVB at 55 $\mathrm{mJ} / \mathrm{cm}^{2}$, covered with a PBS layer. After that, cells were cultivated in nonsupplemented medium for any desired time.

\subsection{Assessment of Oxidative Stress}

2.6.1. ROS Assay. A $2^{\prime}, 7^{\prime}$-dichlorofluorescein-diacetate $\left(\mathrm{DCH}_{2} \mathrm{~F}-\mathrm{DA}\right)$ fluorescence probe (Sigma-Aldrich, France) was employed to detect intracellular ROS levels. Briefly, HaCaT cells were cultivated in 96-well plates $\left(1 \times 10^{4}\right.$ cells/well). After the cells were given NAR pretreatment for $24 \mathrm{hr}$ and exposed to UVB, the cells were immediately rinsed with PBS for 2 times. Next, they were incubated with $10 \mu \mathrm{M}$ of the $\mathrm{DCH}_{2} \mathrm{~F}-\mathrm{DA}$ probe in nonsupplemented medium for $30 \mathrm{~min}$ at $37^{\circ} \mathrm{C}$. Cells were rinsed with PBS for 3 times, and PBS was equally added to cover sample plates afterwards. The fluorescence intensities were measured by using a fluorimeter (Synergy H1, BioTek ${ }^{\circledR}$, USA) with excitation as well as emission spectra of 485 and $528 \mathrm{~nm}$. Images of stained cells were acquired using a fluorescence microscope (Olympus IX50, France).

2.6.2. Nitrite Assay. Nitrite level was employed as a pointer of NO yield secreted into the cell culture medium by the Griess reagent (Sigma-Aldrich). Briefly, cells were cultivated in 6well plates $\left(1 \times 10^{6}\right.$ cells/well $)$. After the cells were given NAR pretreatment for $24 \mathrm{hr}$ and exposed to UVB, the cells were incubated for $24 \mathrm{hr}$. Then, an equal volume of culture supernatants $(50 \mu \mathrm{L})$ together with the Griess reagent (50 $\mu \mathrm{L}$ ) were blended in 96-well plates and incubated at room temperature for $15 \mathrm{~min}$. The absorbance was determined by using a microplate reader at $550 \mathrm{~nm}$ (Multiskan FC, Thermo Fisher Scientific, France). $\mathrm{NaNO}_{2}$ was employed as standard for calculating the concentrations of nitrite.

\subsection{Assessment of Apoptosis}

2.7.1. Caspase-3 Assays. The activity of caspase-3 was determined using the NucView ${ }^{\circledR} 488$ Apoptosis kit (Biotium, Ozyme, France). Briefly, cells were cultivated in 96-well plates $\left(1.0 \times 10^{4}\right.$ cells/well $)$. After the cells were given NAR pretreatment for $24 \mathrm{hr}$ and exposed to UVB, cells were incubated for $10 \mathrm{hr}$. Then, they were rinsed with PBS for 2 times and incubated with $10 \mu \mathrm{M}$ NucView ${ }^{\circledR} 488$ substrate for 30 min at RT in darkness. Next, cells were rinsed with PBS for 3 times, and PBS was equally added to cover sample plates afterwards. The fluorescence signals were measured by using a fluorimeter (Synergy H1) with excitation as well as emis- sion spectra of 485 and $515 \mathrm{~nm}$. Imaging of caspase- 3 activity was performed by fluorescence microscopy (Olympus IX50).

The protein quantity of active caspase-3 was investigated by an Enzyme-Linked Immunosorbent Assay (ELISA). Cells were cultivated in 6 -well plates $\left(1 \times 10^{6}\right.$ cells/well $)$. After the cells were given NAR pretreatment for $24 \mathrm{hr}$ and exposed to UVB, cells were incubated for $10 \mathrm{hr}$. Then, cells were rinsed with PBS, collected by scraping, and cell lysis was continued. The concentration of active caspase- 3 was determined following the manufacturer's protocol (Human Active Caspase-3 Ser29 ELISA Kit, Abcam, UK). Absorbance measurements were made at $450 \mathrm{~nm}$ by using a microplate reader. Values were calculated on the basis of a standard curve. Active caspase-3 levels were normalized to protein contents in cell lysates (determined using the Bradford assay).

2.7.2. TNF- $\alpha$ ELISA. Cells were cultivated in 6-well plates $\left(1 \times 10^{6}\right.$ cells/well $)$. After the cells were given NAR pretreatment for $24 \mathrm{hr}$ and exposed to UVB, cells were incubated for $24 \mathrm{hr}$. Next, culture supernatants were collected. TNF- $\alpha$ quantification was carried out by the human TNF- $\alpha$ quantikine ELISA Kit (R\&D Systems, France). Absorbance measurements were made at $450 \mathrm{~nm}$ by using a microplate reader. Values were calculated on the basis of a standard curve and were normalized to intracellular protein contents.

\subsection{3. $p-p 53, p-p 38 / M A P K$, and NF- $\kappa B$ p65 Expression}

(1) Immunofluorescence Microscopy Imaging. HaCaT cells were cultivated in 8 -well chamber slides $\left(2.5 \times 10^{4}\right.$ cells/well $)$. After the cells were given NAR pretreatment for $24 \mathrm{hr}$ and exposed to UVB, cells were incubated for different times. Then, fixation was performed by incubating $4 \%$ paraformaldehyde solution (PFA) for $10 \mathrm{~min}$ at RT, and further permeabilization was done by incubating $0.1 \%$ Triton X-100 (Sigma-Aldrich) for $15 \mathrm{~min}$ at RT, followed by $1 \mathrm{hr}$ incubation at RT in an appropriate blocking buffer. Cells were immunostained overnight at $4^{\circ} \mathrm{C}$ with phospho-p53 (Ser15) (16G8) Mouse mAb (p-p53) (1:200), phospho-p38/MAPK (Thr180/Tyr182) (28B10) Mouse mAb (p-p38) (1:100), and NF- $\kappa \mathrm{B}$ p65 (D14E12) XP ${ }^{\circledR}$ Rabbit mAb (NF- $\left.\kappa \mathrm{B}\right)(1: 75$, Alexa Fluor ${ }^{\circledR} 488$ Conjugate) (Cell Signaling Technology, Inc., USA). Then, they were incubated for $1 \mathrm{hr}$ at RT with FITC or rhodamine-conjugated antibodies (1:75, SigmaAldrich) and with $4^{\prime}, 6$-diamidine- $2^{\prime}$-phenylindole dihydrochloride (DAPI) solution ( $5 \mu \mathrm{L} / \mathrm{mL}$, Sigma-Aldrich) for $10 \mathrm{~min}$ at RT. Confocal images were acquired with LSM 800 (Zeiss, France) with $\times 63$ objective.

(2) Flow Cytometry. HaCaT cells were cultivated in 6-well plates $\left(1 \times 10^{6}\right.$ cells/well). After the cells were given NAR pretreatment for $24 \mathrm{hr}$ and exposed to UVB, cells were incubated for different times. Then, cells were gathered using trypsin and fixed with $4 \%$ PFA for $10 \mathrm{~min}$ at RT. Flow cytometry staining protocol used the same panel of antibodies (p-p53 diluted at $1: 800, \mathrm{p}-\mathrm{p} 38$ diluted at $1: 100$, and NF- $\kappa \mathrm{B}$ p65 diluted at $1: 50$ ) and procedure as microcopy imaging. Isotype controls were employed in parallel to specifically 
endorse the occurrence of antibody matching, along with the production of the signal gates with positively tagged cells. Cell suspension was done in $2 \mathrm{mM}$ EDTA/PBS before acquisition on an LSR Fortessa Flow Cytometer (Becton Dickinson, France).

\subsection{Assessment of Structural and Biophysical Changes}

2.8.1. Confocal Fluorescence Microscopy. HaCaT cells were cultivated in 8 -well chamber slides $\left(2.5 \times 10^{4}\right.$ cells/well $)$. After the cells were given NAR pretreatment for $24 \mathrm{hr}$ and exposed to UVB, cells were incubated for different times. Then, fixation was performed by incubating 4\% PFA for 10 min. For cytoskeleton as well as nucleus labeling, permeabilization was performed by incubating $0.1 \%$ Triton X-100 for $15 \mathrm{~min}$ at RT. They were double-stained with rhodamine-conjugated phalloidin $(2.5 \mu \mathrm{g} / \mathrm{mL}$, SigmaAldrich) for $15 \mathrm{~min}$ and DAPI solution for $10 \mathrm{~min}$ at RT. For CD95/Fas membrane receptor labelling, cells were incubated for $1 \mathrm{hr}$ at RT in an appropriate blocking buffer, then incubated with anti-Fas Rabbit pAb $(2 \mu \mathrm{g} / \mathrm{mL}$, SigmaAldrich) overnight at $4^{\circ} \mathrm{C}$, followed by incubation for $1 \mathrm{hr}$ at RT with secondary anti-rabbit antibody conjugated with rhodamine (1:75, Sigma-Aldrich). Confocal images were acquired with LSM 800 (Zeiss) with a $\times 63$ objective.

2.8.2. Scanning Electron Microscopy. Fixed cells were dehydrated throughout the set of graded ethanol (ranging from 30 to $100 \%$ ). Drying was taken by the critical point drying (CPD) method (Leica EM CPD030). Coating all samples using a thin gold layer was performed using a Quorum Q150T ES plus. Eventually, samples were scanned using a scanning electron microscope (Hitachi SU8230; Elexience, France).

2.8.3. Membrane Fluidity by TMA-DPH Fluorescence Anisotropy Assay. We used the steady-state fluorescence polarization method [34]. In brief, $\mathrm{HaCaT}$ cells were cultivated in 6-well plates $\left(1 \times 10^{6}\right.$ cells/well $)$ and pretreated with NAR for $24 \mathrm{hr}$. Cells were gathered 2 min after UVB irradiation by gentle scraping in PBS with a cell lifter which left them undamaged. Cells were then labelled with the fluorescent probe TMA-DPH $(2 \mu \mathrm{M})$. Membrane fluidity was assessed $1 \mathrm{~min}$ after cell labelling on a fluorescent spectrophotometer equipped with polarizers (Perkin-Elmer, France). Samples were excited by exposure to vertically polarized light $(360 \mathrm{~nm})$, and emitted light was analyzed at $435 \mathrm{~nm}$ vertically and horizontally to the direction of the excitation. All fluorescent measurements were carried out at $23^{\circ} \mathrm{C}$.

Anisotropy values $(r)$ were calculated as follows:

$$
r=\frac{I_{\mathrm{VV}}-G \times I_{\mathrm{VH}}}{I_{\mathrm{VV}}+2 G \times I_{\mathrm{VH}}},
$$

where $I_{\mathrm{VV}}$ is the emission intensity that is vertically measured, $I_{\mathrm{VH}}$ is the emission intensity that is horizontally measured, and $G$ is the correction factor that is used for calculations in an optical system.
2.9. Statistics. Data are independently represented as means \pm standard deviation (S.D.) of one or three of the experimentations. Each one was operated in triplicate $(n=3)$, and each group was compared using Student's unpaired $t$-test. $p$ $<0.05$ was regarded as significant.

\section{Results}

3.1. The Purity of Artocarpin in the Extract. The amount of artocarpin in the extract was $99.30 \pm 0.03 \% w / w$ according to HPLC. Therefore, this extract was the purified artocarpin extract.

3.2. Protective Effects of NAR versus UVB-Evoked Oxidative Stress in HaCaT Cells. The stimulated ROS inside the cells was detected using the $\mathrm{DCH}_{2} \mathrm{~F}-\mathrm{DA}$ fluorescent probe. Fluorescence spectrometry data showed significantly higher ROS content in UVB-irradiated cells $(143.6 \% \pm 10.1)$ relative to non-UVB-irradiated cells $(100 \% \pm 2.2)$. A significant decrease of intracellular ROS occurred in $\mathrm{HaCaT}$ treated with NAR $(103.9 \% \pm 3.4)$ (Figure $1(\mathrm{~b})$ ). The results were confirmed by fluorescence microscopy observations (Figure 1(a)). NAR inhibited ROS accumulation in UVBexposed cells. Figure 1(c) shows the concentration of nitrite, a major oxidative metabolite of NO, assessed by a Griess reagent assay. The level of nitrite was significantly higher in UVB-exposed HaCaT cells $(9.3 \mu \mathrm{M} \pm 3.7)$, in contrast to non-UVB-exposed HaCaT cells $(0.4 \mu \mathrm{M} \pm 0.3)$ (Figure 1(c)). The NAR pretreatment significantly moderated the nitrite concentration $(3.6 \mu \mathrm{M} \pm 0.2)$. Overall, the results ascribed above indicated that NAR protects keratinocytes out of UVB-caused overproduction of free radicals, called oxidative stress, by scavenging ROS and NO.

\subsection{Protective Effects of NAR versus UVB-Affected HaCaT Apoptosis}

3.3.1. Caspase-3 Assays. As caspase-3 is a crucial protease in the process of apoptosis, we investigated the effect of NAR on the activity of caspase- 3 by using the NucView ${ }^{\circledR} 488$ substrate and then fluorometric measurements. As shown in Figure 2(b), induction of apoptosis by UVB was confirmed with the increase of caspase-3 activity (787 FI \pm 15 for UVB-exposed cells; $578 \mathrm{FI} \pm 12$ for non-UVB-exposed cells). We observed that NAR inhibits caspase-3 activity in UVBexposed cells $(614 \mathrm{FI} \pm 19)$. Microscopic examination also demonstrated a marked increase of green fluorescence after UVB exposure, illustrating activation of caspase-3. Cells pretreated with NAR displayed reduced fluorescence (Figure 2(a)). We next examined active caspase-3 level by ELISA assay (Figure 2(c)). Active caspase-3 concentration was significantly increased in UVB-exposed cells $(17.7 \pm 2.1 \mathrm{ng} / \mathrm{mg}$ protein $)$ compared to non-UVB-exposed cells $(0.4 \pm 0.2 \mathrm{ng} / \mathrm{mg}$ protein $)$. After pretreatment with NAR, the level of active caspase-3 decreased $(8.2 \pm 2.8 \mathrm{ng} / \mathrm{mg}$ protein $)$. Therefore, the protective effect of NAR against UVB-affected $\mathrm{HaCaT}$ apoptosis was mediated in part through caspase-3. There was a positive correlation between the level of active caspase- 3 protein and its activity. 


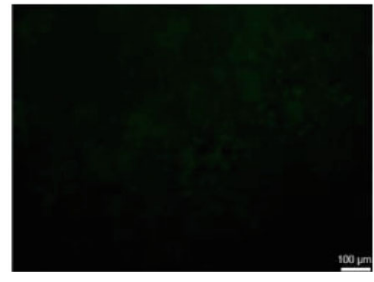

UVB (-)

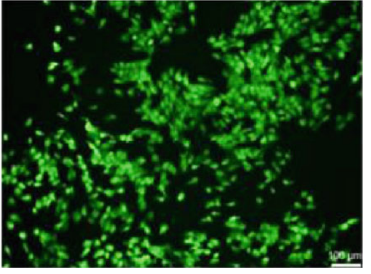

UVB (+)

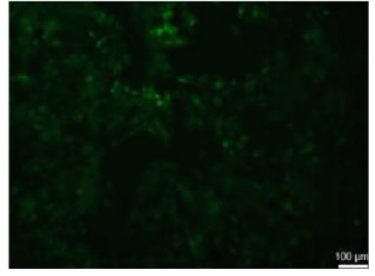

NAR (+) + UVB (+)

(a)

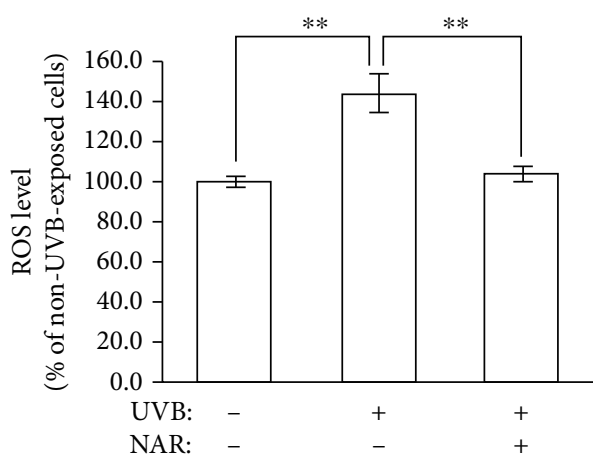

(b)

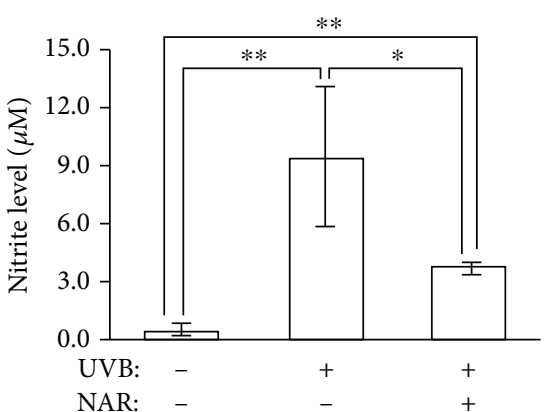

(c)

Figure 1: Antioxidant action by NAR to UVB-exposed HaCaT. The intracellular ROS and nitrite production were measured in HaCaT untreated or treated with NAR $(3.1 \mu \mathrm{g} / \mathrm{mL})$ for $24 \mathrm{hr}$. Immediately after UVB irradiation $\left(55 \mathrm{~mJ} / \mathrm{cm}^{2}\right)$, cells were incubated with the $\mathrm{DCH}_{2} \mathrm{~F}-\mathrm{DA}$ probe to detect ROS level by (a) fluorescence microscopy and (b) fluorimetry (excitation: $485 \mathrm{~nm}$; emission: $528 \mathrm{~nm}$ ). (c) Later on, $24 \mathrm{hr}$ after UVB irradiation, media were collected, and nitrite level was measured by the Griess assay spectrophotometrically at $550 \mathrm{~nm}$. Three of experimentations were operated. Each one was done in triplicate $(n=3)$. Results are mean \pm S.D. ${ }^{*} p<0.05$ and ${ }^{* *} p<$ 0.01 , using Student's unpaired $t$-test.

3.3.2. Apoptosis-Related Molecules and Signaling Pathways. We studied the expression of different apoptosis-related molecules including p-p53, p-p38, the subunit NF- $\kappa \mathrm{B}$ p65, and TNF- $\alpha$ (Figure 3 ). As some protein functions are regulated through posttranslational modifications, such as phosphorylation, we examined phosphorylated proteins. Immunofluorescence analysis by microscopy showed that p-p53, p-p38, and NF- $\kappa$ B p65 expression was upregulated after UVB irradiation (Figure 3(a)). Similar to p-p38, the staining of p-p53 was localized in the nucleus, whereas the staining of NF- $\kappa \mathrm{B}$ p65 was mainly in the cytoplasm. For the NAR-pretreated UVB-exposed cells, the expression of these molecules was reduced compared to UVB-exposed cells. Flow cytometry data confirmed fluorescence microscopy imaging and therefore reported a significant effect of NAR on some particular signaling cascades transmitted and transcription factors linked to the cellular response to UVB-affected apoptosis $(\% \mathrm{p}-\mathrm{p} 53$ fluorescence intensity $=9.2 \pm 1.0$ and $4.0 \pm 1.2$ for UVB-irradiated vs. NAR-pretreated UVB-irradiated cells, respectively; $\% \mathrm{p}-\mathrm{p} 38$ fluorescence intensity $=13.2 \pm 0.9$ and $6.9 \pm 1.2$ for UVB-irradiated vs. NAR-pretreated UVBirradiated cells, respectively; $\% \mathrm{NF}-\kappa \mathrm{B}$ p 65 fluorescence intensity $=12.9 \pm 1.8$ and $7.2 \pm 1.3$ for UVB-irradiated vs. NAR-pretreated UVB-irradiated cells, respectively; Figure 3(b)).

Additionally, we also investigated by ELISA assay the production of TNF- $\alpha$, a proinflammatory and apoptosisinducing cytokine (Figure 3(c)). After UVB irradiation, TNF- $\alpha$ was significantly upsecreted in UVB-exposed cells
$(28.3 \pm 4.3 \mathrm{pg} / \mathrm{mg}$ protein), compared to non-UVB-exposed cells $(7.7 \pm 0.3 \mathrm{pg} / \mathrm{mg}$ protein $)$. NAR pretreatment significantly inhibited the secretion of TNF- $\alpha$ by UVB-exposed cells $(11.8 \pm 4.0 \mathrm{pg} / \mathrm{mg}$ protein $)$.

\subsection{Protective Effects of NAR versus UVB-Influenced Structural and Biophysical Changes}

3.4.1. Nucleus, F-Actin Cytoskeleton, and CD95/Fas Membrane Receptor. Changes in nuclei, F-actin cytoskeleton, and CD95/Fas cell surface receptor were studied by confocal laser scanning microscopy (Figure 4(a)). DAPI and rhodamine-phalloidin staining and anti-CD95/Fas immunostaining showed that UVB exposure causes, respectively, nuclei condensation and fragmentation with apoptotic body formation; impaired cell adherence and round cell shape; disruption of actin filament and weaker F-actin labelling; and CD95/Fas clustering with stronger labelling. Therefore, we confirmed that UVB exposure leads to characteristic apoptotic cell patterns. The NAR-pretreated cells exhibited a nonUVB-like cell shape with uniformity in cell nuclei (large and round), a highly polymerized F-actin filament, and a loss of anti-CD95/Fas clustering. In the presence of NAR, there was a marked absence of UVB-induced structural cell damages.

3.4.2. SEM Cell Morphology. Cell surface morphology was observed by SEM imaging (Figures 4(b)). Non-UVBexposed cultures showed a uniform cell layer including 


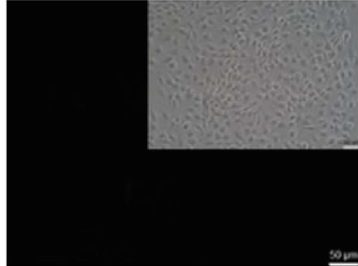

$\operatorname{UVB}(-)$

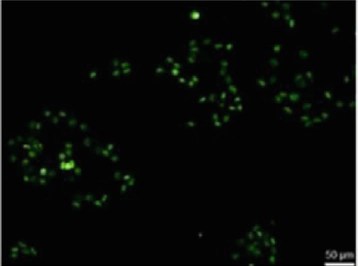

$\operatorname{UVB}(+)$

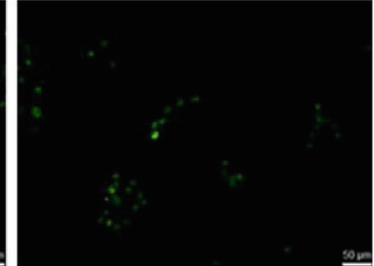

$\operatorname{NAR}(+)+\operatorname{UVB}(+)$

(a)

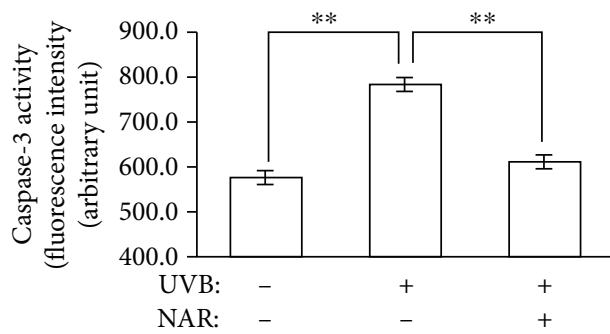

(b)

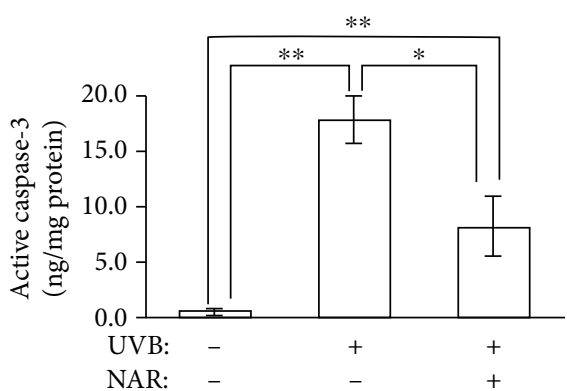

(c)

Figure 2: Protective effects of NAR versus UVB-affected apoptosis. The caspase-3 activity and the level of active caspase-3 protein were measured in HaCaT untreated or treated with NAR $(3.1 \mu \mathrm{g} / \mathrm{mL})$ for $24 \mathrm{hr}$. At $10 \mathrm{hr}$ after UVB irradiation $\left(55 \mathrm{~mJ} / \mathrm{cm}^{2}\right)$, cells were gathered and the NucView ${ }^{\circledR} 488$ substrate was added to detect caspase-3 activity by (a) fluorescence microscopy and (b) fluorimetry (excitation: $485 \mathrm{~nm}$; emission: $515 \mathrm{~nm}$ ). (c) The quantity of active caspase-3 protein was detected by human active caspase-3 Ser-29 ELISA assay. Three of experimentations were operated. Each one was done in triplicate $(n=3)$. Results are mean \pm S.D. ${ }^{*} p<0.05$ and ${ }^{* *} p<0.01$, using Student's unpaired $t$-test.

polygonal and flattened cells with numerous protrusions (Figures 4(b)1a and 4(b)1b), whereas UVB-exposed cultures exhibited various cell shapes-cell flattening and cell rounding with cytoplasmic retraction and membrane blebbing characteristic of apoptotic cells (white arrows) (Figures 4(b)2a and 4(b)2b). The NAR-pretreated UVBexposed cells were mostly flattened and spread with protrusions (Figures 4(b)3a and 4(b)3b). Therefore, NAR protected cells against morphological features induced by UVB exposure.

3.4.3. Cell Membrane Fluidity. The fluidity of a membrane was appraised by means of the fluorescent anisotropy $(r)$ of TMA-DPH, owing to the positive charge of its amino group, which is anchored at the surface of the cell membrane. The measurement of fluorescence polarization was used to determine the rotational diffusion of the probe (Figure 5). After 2 min of TMA-DPH labelling, fluorescence anisotropy values $(r)$ of the UVB-exposed cells were significantly higher, in contrast to those of the non-UVB-exposed cells. This trend did not change during incubation time. Data showed that UV exposure induces a less fluid lipid bilayer and thereby alters the plasma membrane structure. The NAR pretreatment decreased the fluorescence anisotropy of TMA-DPH of UVB-exposed cells, with values close to those of nonUVB-exposed cells (at $4 \mathrm{~min}$ after labelling, $r=0.244$ for non-UVB-exposed cells, $r=0.254$ for UVB-exposed cells, and $r=0.246$ for NAR-pretreated UVB-exposed cells). The NAR used on non-UVB-exposed cells did not affect to cell membrane fluidity (data not displayed). Thus, NAR prevented the loss of cell membrane fluidity after UVB exposure.

\section{Discussion}

The deleterious effects of excessive exposure to UVB bring about skin disorders: inflammatory skin, hyperplasia, premature aging of the skin, and skin cancer [4]. NAR is known as a natural flavonoid compound with a purity of around 99\%, isolated from the Artocarpus altilis plant's heartwood by using diethyl ether. This active compound possesses several pharmacological properties and biological activities described in the literature: antioxidation [27-33], antiinflammation [30, 32], tyrosinase and melanogenesis inhibition [27-29], and antimicrobial activity [34]. In this study, our results offer evidence that NAR is able to shield the detrimental effects of UVB irradiation. The biological basis for the efficacy of NAR was described and complemented our preceding findings (Figure 6).

Sunburn cells, an outstanding event caused by excessive exposure to UV, are due to the occurrence of apoptotic cells named keratinocytes, inducing death within the epidermis. Inappropriate apoptosis can contribute to skin malignancies and cancer; consequently, control of apoptosis is an important target for an effective photoprotection [7]. Here, we used an in vitro cell line HaCaT model to study the effect of NAR. Epidermal keratinocytes were irradiated with UVB at a single intensity of $55 \mathrm{~mJ} / \mathrm{cm}^{2}$ to trigger apoptosis, following the procedure as shown by Luangpraditkun et al. in 2020 [33]. Sorting from low, moderate, and high amounts of UVB, the diverse features of cell death can be induced by running from apoptosis without inflammation, to apoptosis with a proinflammatory cytokine, and eventually up to necrosis with inflammation [35]. Our previous data showed that apoptosis 


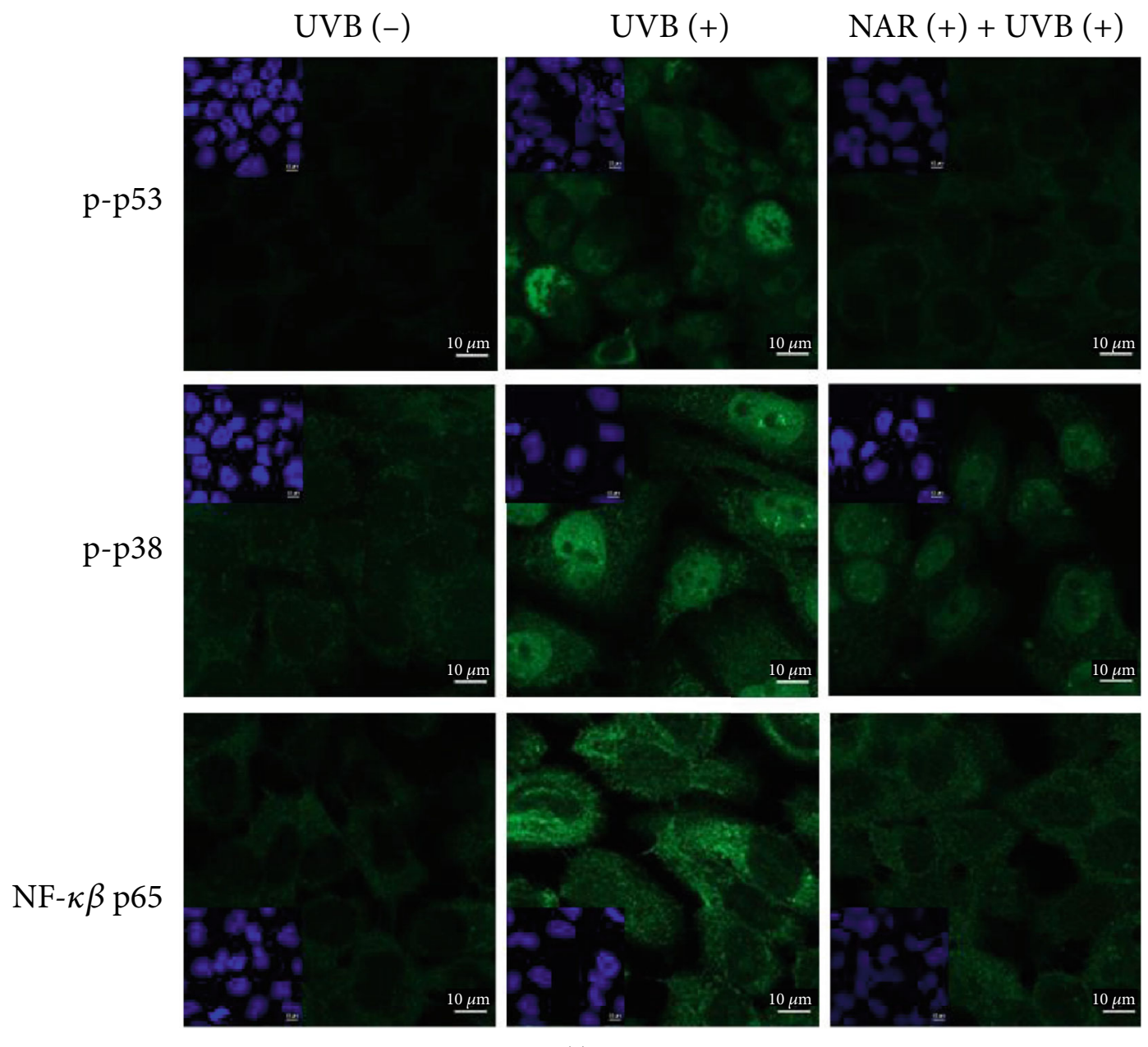

(a)

Figure 3: Continued. 

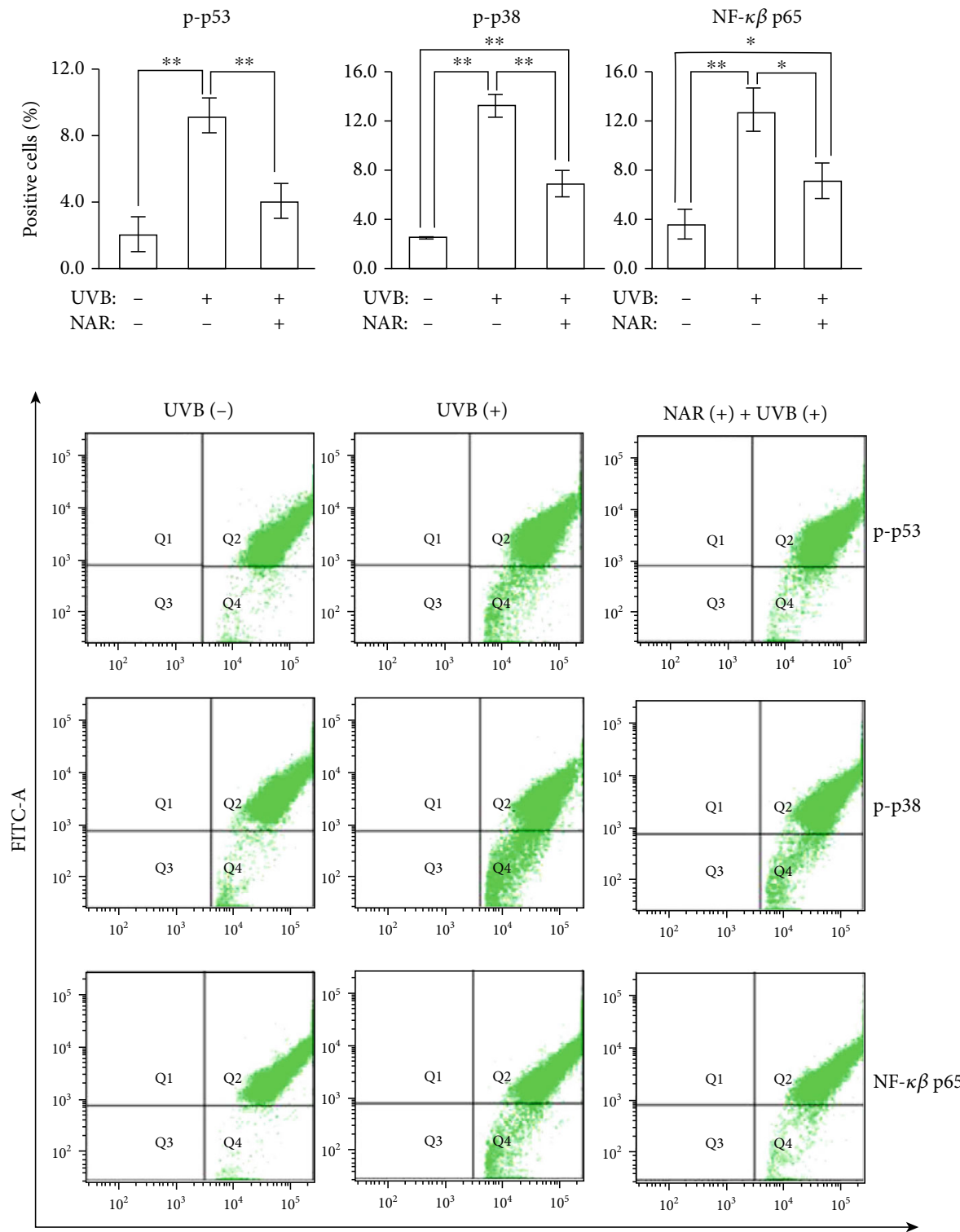

FSC-A

(b)

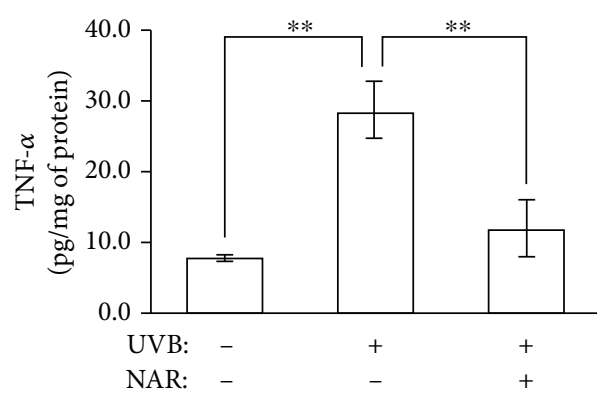

(c)

FIGURE 3: Protective effects of NAR against apoptosis-related molecules and signaling pathways. Immunofluorescence staining $6 \mathrm{hr}$ after UVB irradiation $\left(55 \mathrm{~mJ} / \mathrm{cm}^{2}\right)$ for p-p53, p-p38, and NF- $\kappa$ B p65, in HaCaT untreated or treated with NAR $(3.1 \mu \mathrm{g} / \mathrm{mL})$ for $24 \mathrm{hr}$. (a) Representative confocal microscopy images (63x objective magnification). (b) Flow cytometry analyses with histograms and representative p-p53, p-p38, and NF- $\kappa$ B p 65 dot plots. (c) Human TNF- $\alpha$ quantikine ELISA assay $24 \mathrm{hr}$ after UVB irradiation $\left(55 \mathrm{~mJ} / \mathrm{cm}^{2}\right)$ in supernatants of HaCaT untreated or treated with NAR. One $(\mathrm{a}, \mathrm{b})$ or three $(\mathrm{c})$ experimentations were independently performed. Each one was done in triplicate $(n=3)$. Results are mean \pm S.D. ${ }^{*} p<0.05$ and ${ }^{* *} p<0.01$, using Student's unpaired $t$-test. 


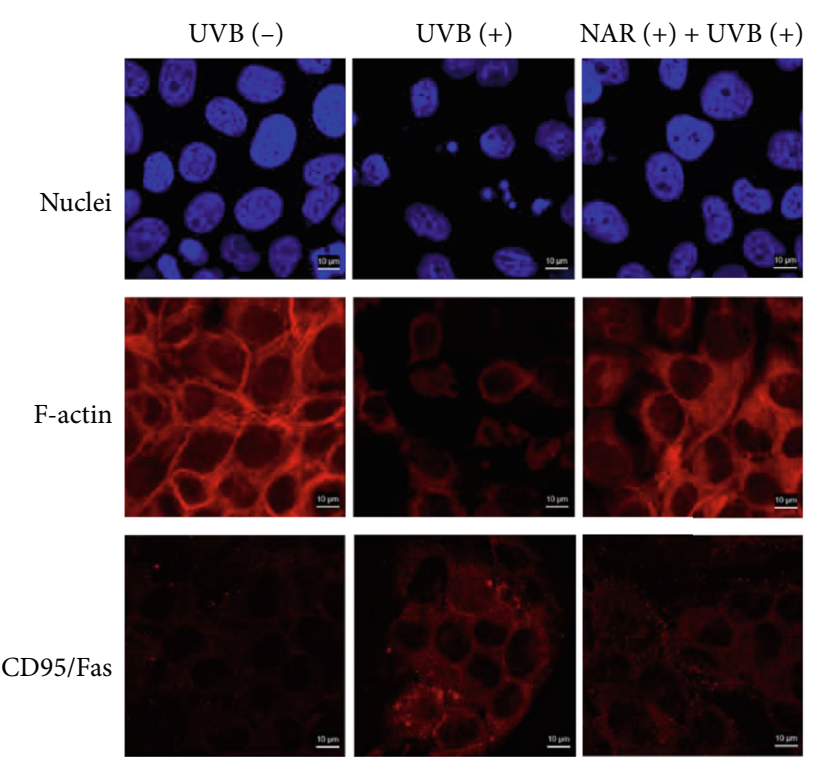

(a)

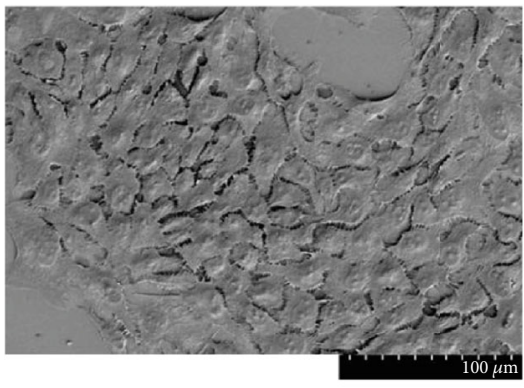

(1a)

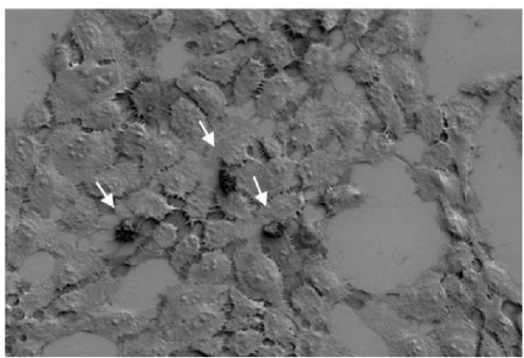

(2a)

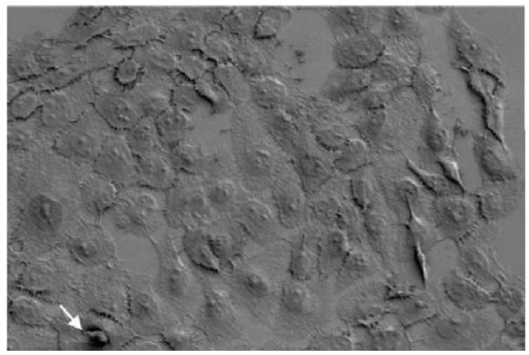

(3a)

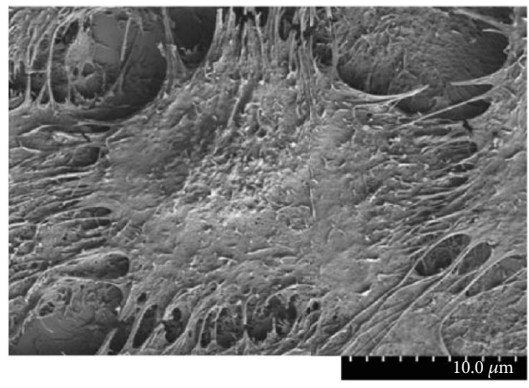

(1b)

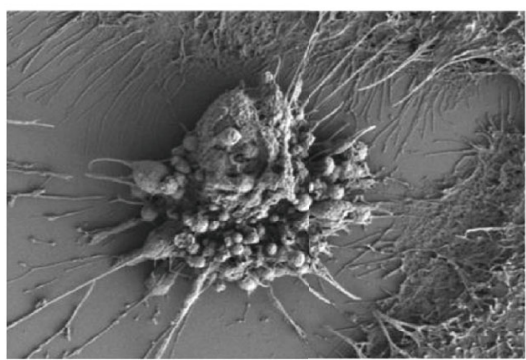

(2b)

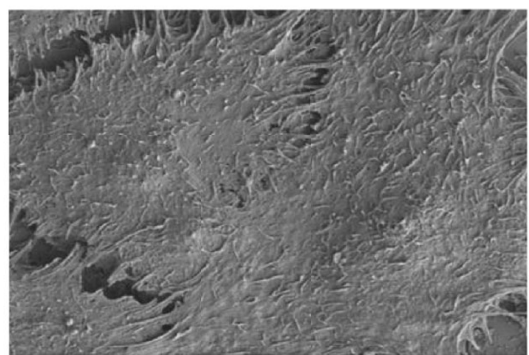

(3b)

(b)

FIgURE 4: Protective effects of NAR against UVB-induced structural changes. Representative imaging of HaCaT cells untreated or treated with NAR $(3.1 \mu \mathrm{g} / \mathrm{mL})$ for $24 \mathrm{hr}$, at $10 \mathrm{hr}$ after UVB irradiation $\left(55 \mathrm{~mJ} / \mathrm{cm}^{2}\right.$ ). (a) Confocal microscopy of HaCaT for nuclei (DAPI staining), F-actin (rhodamine-phalloidin staining), and CD95/Fas (anti-CD95/Fas rabbit pAb and secondary anti-rabbit antibody conjugated with rhodamine) (63x objective magnification). (b) SEM of non-UVB-exposed cells (1a, 1b), UVB-exposed cells (2a, 2b), and NAR-pretreated UVB-exposed cells (3a, 3b). 
induced with a physiological dose of $55 \mathrm{~mJ} / \mathrm{cm}^{2} \mathrm{UVB}$ was initiated by CPD lesions in DNA as well as ROS production, and mediated by caspase- 3 and 8 activation [33]. In this work, we investigated other relevant markers of apoptosis to analyze the complete UVB response. Our analyses showed a significant overproduction of ROS and nitrite (nitrites are a metabolized form of NO reaction) following UVB expression and a significant reduction of these levels with the NAR pretreatment. We presented that the antioxidant effect of NAR is linked throughout its potentiality to scavenge ROS and NO. Being a free radical scavenger is an ordinary feature among different flavonoids and has been constituted by the hydroxyl groups to highly and reactively counteract to ROS and RNS $[36,37]$. Flavonoids donate their hydrogen atoms for neutralizing free radicals. Flavonoid compounds thus display various antioxidant capabilities and have different impacts on free radical species. It is clear from the data of an in vitro study which demonstrated that the hydroxyl group figures of flavonoids are an eminent point for indicating their capabilities towards antioxidants and their effectiveness of free radical scavenging [38]. Furthermore, the overproduced ROS can interact with RNS such as NO to produce peroxynitrite anion $\left(\mathrm{ONOO}^{-}\right)$which is an extremely reactive radical. Studies have reported that $\mathrm{ONOO}^{-}$activates apoptosis through p38 mitogen-activated protein kinases (MAPKs) and c-Jun $\mathrm{N}$-terminal kinase (JNK) cascades. NO has been reported to degrade an antiapoptotic protein, namely, the myeloid cell leukemia 1 (Mcl-1) and activate dead cells via the apoptosis signal-regulating kinase- (ASK1-) JNK and BAX/BAK-activated caspase cascades [39]. Taken together, these data suggested that NAR confers direct antioxidant protection and thereby indirect antiapoptotic protection to cells.

Overproduction of intracellular ROS can overwhelm the antioxidant defenses and attack important cell components including membrane lipids, proteins, and DNA [20, 40]. Free radicals generated by UVB irradiation are implicated in oxidative cell membrane damages, such as membrane fluidity changes. Cellular membranes are highly dynamic structures. Thus, maintaining their structural integrity, their fluidity, and their rotational, translational, and transbilayer lipid movement is indispensable to preserve cell function [11, 41]. We used the TMA-DPH hydrophobic probe which incorporates instantaneously into the plasma membrane and becomes fluorescent. We measured its transbilayer movement characterizing the membrane fluidity. We showed that UV irradiation reduces the fluidity of the lipid membrane. This effect was due to the repression of the transbilayer phospholipid movement by free radicals [12]. Membrane phospholipids are easily oxidized by ROS and NO overproduction. Lipid peroxidation is a dominant hallmark to state the effect of UVB-induced skin disorders. We reported that the NAR pretreatment prevents membrane rigidification induced by ROS and nitrite. Our previous data supported that NAR reduces lipid peroxidation products (LPOs) in vitro [33]. In addition, it has been shown that a topical treatment with artocarpin on hairless mice before UVB exposure decreases LPOs [30]. Therefore, the degradation of membrane lipids generates pathological conditions in

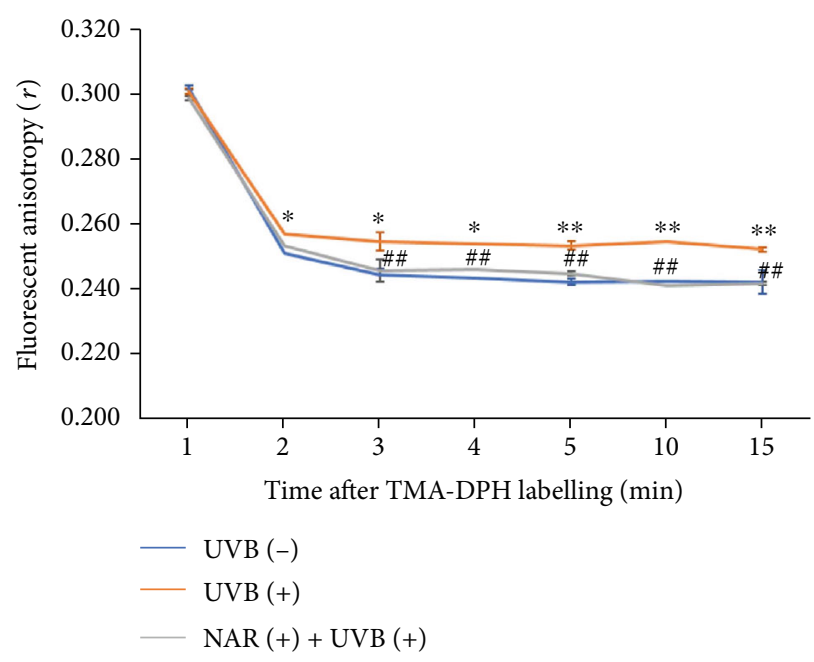

FIgURE 5: Protective effects of NAR versus UVB-influenced biophysical changes. Measurement of fluorescent anisotropy of TMA-DPH in HaCaT cells untreated or treated with NAR (3.1 $\mu \mathrm{g} / \mathrm{mL})$ for $24 \mathrm{hr}$, at $2 \mathrm{~min}$ after UVB exposure $\left(55 \mathrm{~mJ} / \mathrm{cm}^{2}\right)$. An experimentation was operated in triplicate $(n=3)$. Results are mean \pm S.D. ${ }^{*} p<0.05$ and ${ }^{* *} p<0.01$, compared between UVB (-) and UVB $(+) .{ }^{\# \#} p<0.01$, compared between UVB $(+)$ and NAR $(+)+$ UVB (+), using Student's unpaired $t$-test.

cells as a loss of membrane fluidity, an increase of membrane permeability, and eventually a breakdown of the plasma membrane causing cell death [15]. We confirmed that NAR alone or nonexposure to UV provides important antioxidant benefits, particularly in a lack of any indications of a significant change of membrane fluidity. Although the exact location of NAR in the lipid membrane is not precisely realized, we hypothesized that NAR intercalates the membrane lipid bilayer preferentially in the lipid rafts because most of the flavonoids, including NAR, are poorly water soluble.

A less fluid lipid bilayer event impedes transbilayer movement of phospholipids (flip-flop) and can induce clustering and activation of membrane receptors. CD95/Fas is an ubiquitously expressed cell surface receptor belonging to the TNF-R superfamily, involved in the apoptosis process. Our results validated that UVB irradiation activates the CD95/Fas receptor on $\mathrm{HaCaT}$ cells independently of the natural ligand CD95L, whereas the NAR pretreatment reduces its activation. Prevention of UVB-induced CD clustering by NAR was also associated with a preservation of cell morphology and a significant reduction of apoptosis markers. After UV exposure, we observed typical morphological features of apoptosis, such as a disruption of the actin cytoskeleton, nuclear condensation, membrane blebbing, and apoptotic body formation. In the presence of NAR, there was a marked reduction or absence of these hallmarks. It has been reported that ROS affect cytoskeleton proteins $[42,43]$. Thus, the NAR pretreatment indirectly protected cytoskeletal components through its free radical scavenging potential. It has been demonstrated that the disrupted actin cytoskeleton can be conducted by activating CD95/Fas, and finally results in apoptosis [44]. It is well known that apoptosis affected by UVB is initiated by ROS as well as DNA damage and is 


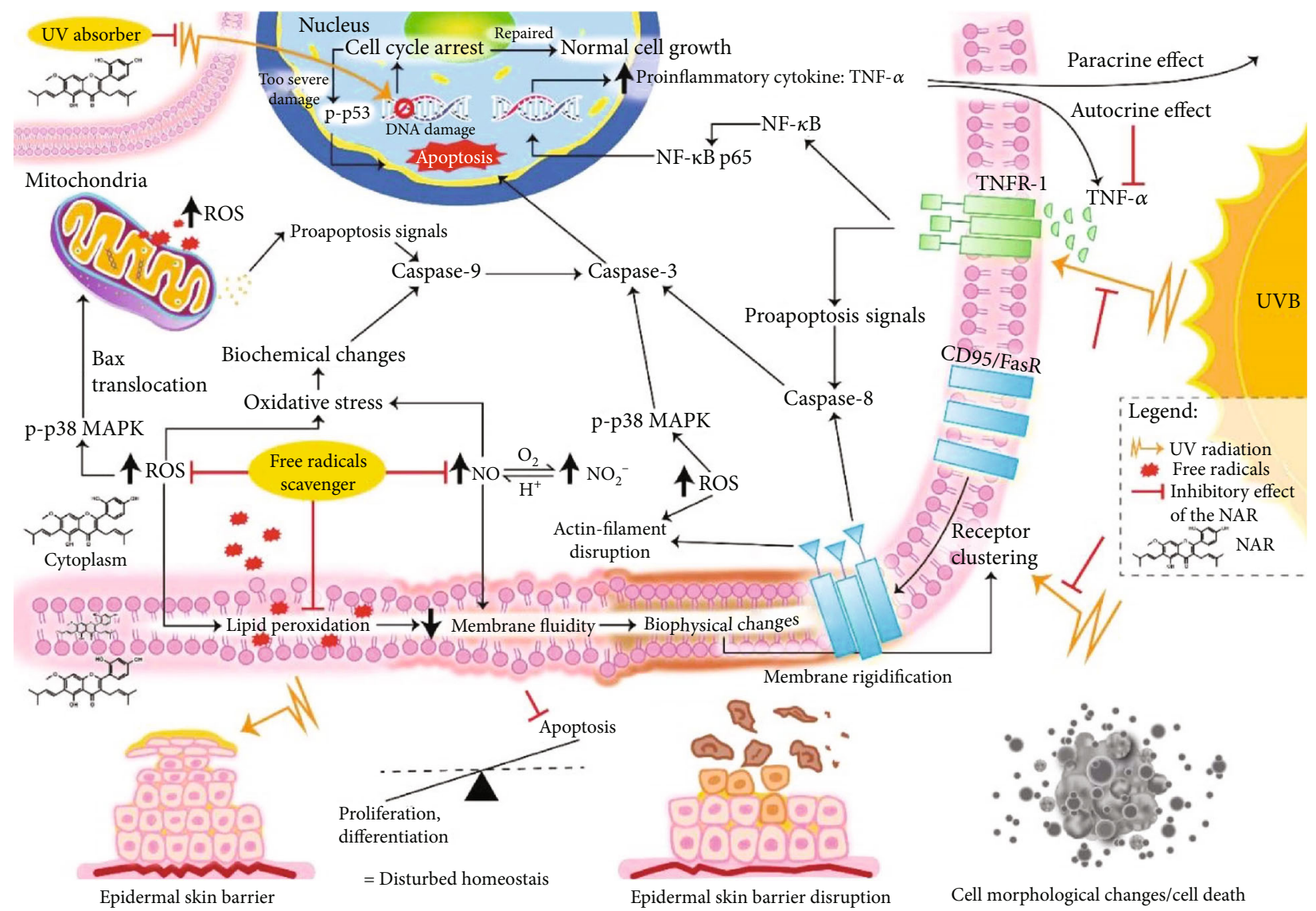

FIgURE 6: Schema displaying the mechanism of NAR against UVB-induced cell alterations. Exposure to UVB radiation induces massive apoptosis that contributes to skin photoaging and skin carcinogenesis. Apoptosis is an extremely regulated process that relates to a set of cellular events orchestrated mainly by the activation of caspases and leading to cell death. Signaling for UVB-induced apoptosis occurs through DNA damages and high levels of free radicals (ROS and NO), which initiate many cellular responses: (a) differential expression of p53 including halting of the cell cycle, repairing of DNA, and inducing cell death (apoptosis pattern); (b) p38 MAPK and NF- $\kappa$ B pathway activation; (c) cell death membrane receptor activation (CD95/Fas) and proinflammatory cytokine secretion (TNF- $\alpha$ ); and (d) damage to structural cell components (actin cytoskeleton, nucleus, and plasma membrane). NAR is a natural bioactive compound which is capable of both absorbing UV and scavenging free radicals, thereby showing an effective antioxidant capacity. It modulates intracellular signaling via direct interaction with free radicals, playing an antiapoptotic effect. It protects cells from the morphological and biochemical features of UVB-induced apoptosis, and therefore maintains skin homeostasis. We hypothesis that NAR is distributed in different cellular compartments as other antioxidant flavonoids, contributing to enhance its photoprotective effect.

mediated by a diverse array of signaling cascades, most of which are ultimately coupled to the activation of effector caspases. We found that NAR reduces the activation and thereby the activity of caspase- 3 , a crucial proteolytic enzyme of cell death signals, after UVB exposure. The function of many apoptosis-related signaling molecules, like p53, p38 MAPK, and NF- $\kappa \mathrm{B}$ p65 is regulated through posttranslational modifications, such as phosphorylation. Therefore, we studied the expression of these phosphorylated signal transducers and showed that they are stimulated when $\mathrm{HaCaT}$ cells are exposed to UVB and are so reduced among cells pretreated with NAR before exposing to UVB. Additionally, TNF- $\alpha$ is a critical regulator of both apoptosis and inflammation by mediating TNF receptor-associated intracellular signaling complexes [45]. Our data clarified that UVB radiation promotes TNF- $\alpha$ secretion by HaCaT cells, whereas the NAR pretreatment could decrease it. The antioxidant property by NAR mediated the inhibition of TNF- $\alpha$ - induced cell surface death receptor activation (TNF-R) through suppression of NF- $\kappa$ B signaling. The paracrine effect of TNF- $\alpha$ cytokine from epidermal keratinocytes upregulated by UVB is associated with the loss of skin structural integrity by inducing dermal matrix metalloproteinases (MMPs) which have extracellular matrix-destructive potential [46]. Taken together, NAR could shield the detrimental effects of UV exposure by inducing the inhibition of apoptosis.

\section{Conclusion}

Exogenous antioxidants represent a safe and effective strategy to protect the human skin against UV-caused damage [47]. All the results of the present in vitro study highlighted the efficacy of NAR in epidermal photoprotection. NAR acts directly from scavenging free radicals generated by UV and indirectly by suppressing morphological and biochemical UV-induced cell damages. Its biological effects are mainly 
attributed to antioxidant and antiapoptotic properties. Thus, whereas natural products are popular in the field of biological sciences and pharmaceutical research $[48,49]$ and in the skincare market, NAR represents an effective natural ingredient in sunscreens.

\section{Data Availability}

The data used to support the findings of this study have been deposited in the Hindawi repository [doi:10.1155/ 2020/1042451].

\section{Conflicts of Interest}

The authors declare that they have no conflicts of interest.

\section{Acknowledgments}

We thank the DImaCell Imaging facility (INRAE, Bourgogne Franche-Comté University, Dijon, France). This work has received grant support from the Royal Golden Jubilee (RGJ) Ph.D. Programme (Scholarship No. PHD/0021/2557) and the Embassy of France in Thailand under the RGJ Ph.D. Programme for funding sources of both research and graduate student. We are also thankful for the Center of Excellence for Innovation in Chemistry (PERCH-CIC) for the support on whole facilities.

\section{References}

[1] H. Green, "Terminal differentiation of cultured human epidermal cells," Cell, vol. 11, no. 2, pp. 405-416, 1977.

[2] E. Reefman, P. C. Limburg, C. G. M. Kallenberg, and M. Bijl, "Apoptosis in human skin: role in pathogenesis of various diseases and relevance for therapy," Annals of the New York Academy of Sciences, vol. 1051, no. 1, pp. 52-63, 2005.

[3] J. Lee, J. Y. Cho, S. Y. Lee, K. W. Lee, J. Lee, and J. Y. Song, "Vanillin protects human keratinocyte stem cells against ultraviolet B irradiation," Food and Chemical Toxicology, vol. 63, pp. 30-37, 2014.

[4] Y. Matsumura and H. N. Ananthaswamy, "Toxic effects of ultraviolet radiation on the skin," Toxicology and Applied Pharmacology, vol. 195, no. 3, pp. 298-308, 2004.

[5] X. L. Mei and S. Lian, "Ultraviolet B light-induced apoptosis in human keratinocytes enriched with epidermal stem cells and normal keratinocytes," Chinese Medical Journal, vol. 124, no. 4, pp. 591-598, 2011.

[6] P. Virag, I. C. Brie, C. C. Burz et al., "Modulation of the UV-Binduced oxidative stress and apoptosis in $\mathrm{HaCaT}$ cell line with Calluna vulgaris extract," Notulae Botanicae Horti Agrobotanici Cluj-Napoca, vol. 43, no. 2, pp. 313-319, 2015.

[7] D. Raj, D. E. Brash, and D. Grossman, "Keratinocyte apoptosis in epidermal development and disease," Journal of Investigative Dermatology, vol. 126, no. 2, pp. 243-257, 2006.

[8] S. J. Jiang, J. Y. Chen, Z. F. Lu, J. Yao, D. F. Che, and X. J. Zhou, "Biophysical and morphological changes in the stratum corneum lipids induced by UVB irradiation," Japanese Society for Investigative Dermatology, vol. 44, no. 1, pp. 29-36, 2006.

[9] M. A. el-Mahdy, Q. Zhu, Q. E. Wang et al., "Naringenin protects HaCaT human keratinocytes against UVB-induced apoptosis and enhances the removal of cyclobutane pyrimidine dimers from the genome," Photochemistry and Photobiology, vol. 84, no. 2, pp. 307-316, 2008.

[10] H. L. Lo, S. Nakajima, L. Ma et al., "Differential biologic effects of CPD and 6-4PP UV-induced DNA damage on the induction of apoptosis and cell-cycle arrest," Biomed Central Cancer, vol. 5, no. 1, pp. 135-143, 2005.

[11] F. Gaboriau, P. Morlière, I. Marquis, A. Moysan, M. Goegze, and L. Dubertret, "Membrane damage induced in cultured human skin fibroblasts by UVA irradiation," Photochemistry and Photobiology, vol. 58, no. 4, pp. 515-520, 1993.

[12] G. Deliconstantinos, V. Villiotou, and J. C. Stavrides, "Increase of particulate nitric oxide synthase activity and peroxynitrite synthesis in UVB-irradiated keratinocyte membranes," Biochemical Journal, vol. 320, no. 3, pp. 997-1003, 1996.

[13] L. J. Su, J. H. Zhang, H. Gomez et al., "Reactive oxygen speciesinduced lipid peroxidation in apoptosis, autophagy, and ferroptosis," Oxidative Medicine and Cellular Longevity, vol. 2019, Article ID 5080843, 13 pages, 2019.

[14] M. Xiao, H. Zhong, L. Xia, Y. Tao, and H. Yin, "Pathophysiology of mitochondrial lipid oxidation: role of 4hydroxynonenal (4-HNE) and other bioactive lipids in mitochondria," Free Radical Biology and Medicine, vol. 111, pp. 316-327, 2017.

[15] X. Zhu, N. Li, Y. Wang et al., "Protective effects of quercetin on UVB irradiation-induced cytotoxicity through ROS clearance in keratinocyte cells," Oncology Reports, vol. 37, no. 1, pp. 209-218, 2017.

[16] V. Muthusamy and T. J. Piva, "The UV response of the skin: a review of the MAPK, NF $\kappa$ B and TNF $\alpha$ signal transduction pathways," Archives of Dermatological Research, vol. 302, no. 1, pp. 5-17, 2010.

[17] H. Shimizu, Y. Kitajima, Y. Banno, N. Sumi, T. Naganawa, and Y. Nozawa, "Activation of p38 mitogen-activated protein kinase and caspases in UVB-induced apoptosis of human keratinocyte HaCaT cells," The Journal of Investigative Dermatology, vol. 112, no. 5, pp. 769-774, 1999.

[18] A. van Laethem, S. van Kelst, S. Lippens et al., "Activation of p38 MAPK is required for Bax translocation to mitochondria, cytochrome $\mathrm{c}$ release and apoptosis induced by UVB irradiation in human keratinocytes," Federation of American Societies for Experimental Biology, vol. 18, no. 15, pp. 1946-1948, 2004.

[19] J. S. Fridman and S. W. Lowe, "Control of apoptosis by p53," Oncogene, vol. 22, no. 56, pp. 9030-9040, 2003.

[20] Z. Assefa, A. van Laethem, M. Garmyn, and P. Agostinis, "Ultraviolet radiation-induced apoptosis in keratinocytes: on the role of cytosolic factors," Biochimica et Biophysica Acta (BBA) - Reviews on Cancer, vol. 1755, no. 2, pp. 90-106, 2005.

[21] D. Kulms and T. Schwarz, "Molecular mechanisms of UVinduced apoptosis," Photodermatology, Photoimmunology \& Photomedicine, vol. 16, no. 5, pp. 195-201, 2000.

[22] M. Redza-Dutordoir and D. A. Averill-Bates, "Activation of apoptosis signalling pathways by reactive oxygen species," Biochimica et Biophysica Acta, vol. 1863, no. 12, pp. 2977-2992, 2016.

[23] A. Yamada, R. Arakaki, M. Saito, Y. Kudo, and N. Ishimaru, "Dual role of Fas/FasL-mediated signal in peripheral immune tolerance," Frontiers in Immunology, vol. 8, pp. 1-10, 2017.

[24] R. C. Budd, "Death receptors couple to both cell proliferation and apoptosis," Journal of Clinical Investigation, vol. 109, no. 4, pp. 437-442, 2002. 
[25] Y. Aragane, D. Kulms, D. Metze et al., "Ultraviolet light induces apoptosis via direct activation of CD95 (Fas/APO-1) independently of its ligand CD95L," The Journal of Cell Biology, vol. 140, no. 1, pp. 171-182, 1998.

[26] R. J. Nijveldt, E. van Nood, D. E. C. van Hoorn, P. G. Boelens, K. van Norren, and P. A. M. van Leeuwen, "Flavonoids: a review of probable mechanisms of action and potential applications," The American Journal of Clinical Nutrition, vol. 74, no. 4, pp. 418-425, 2001.

[27] P. Donsing, N. Limpeanchob, and J. Viyoch, "Evaluation of the effect of Thai breadfruit's heartwood extract on melanogenesis-inhibitory and antioxidation activities," International Journal of Cosmetic Science, vol. 59, pp. 41-58, 2008.

[28] S. Buranajaree, P. Donsing, R. Jeenapongsa, and J. Viyoch, "Depigmenting action of a nanoemulsion containing heartwood extract of Artocarpus incisus on UVB-induced hyperpigmentation in C57BL/6 mice," International Journal of Cosmetic Science, vol. 62, pp. 1-14, 2011.

[29] W. C. Lan, C. W. Tzeng, C. C. Lin, F. L. Yen, and H. H. Ko, "Prenylated flavonoids from Artocarpus altilis: antioxidant activities and inhibitory effects on melanin production," Phytochemistry, vol. 89, pp. 78-88, 2013.

[30] C. W. Lee, H. H. Ko, C. C. Lin, C. Y. Chai, W. T. Chen, and F. L. Yen, "Artocarpin attenuates ultraviolet B-induced skin damage in hairless mice by antioxidant and antiinflammatory effect," Food and Chemical Toxicology, vol. 60, pp. 123-129, 2013.

[31] K. Itsarasook, K. Ingkaninan, and J. Viyoch, "Artocarpinenriched extract reverses collagen metabolism in UVexposed fibroblasts," Biologia, vol. 69, no. 7, pp. 943-951, 2014.

[32] N. Tiraravesit, S. Yakaew, R. Rukchay et al., “Artocarpus altilis heartwood extract protects skin against UVB_in vitro_ and _in vivo_," The Journal of Ethnopharmacology, vol. 175, pp. 153-162, 2015.

[33] K. Luangpraditkun, P. Charoensit, F. Grandmottet, C. Viennet, and J. Viyoch, "Photoprotective potential of the natural artocarpin against in vitro UVB-induced apoptosis," Oxidative Medicine and Cellular Longevity, vol. 2020, 17 pages, 2020.

[34] C. Pradhan, M. Mohanty, and A. Rout, "Phytochemical screening and comparative bioefficacy assessment of Artocarpus altilis leaf extracts for antimicrobial activity," Frontiers in Life Science, vol. 6, no. 3-4, pp. 71-76, 2012.

[35] R. Caricchio, L. McPhie, and P. L. Cohen, "Ultraviolet B radiation-induced cell death: critical role of ultraviolet dose in inflammation and lupus autoantigen redistribution," The Journal of Immunology, vol. 171, no. 11, pp. 5778-5786, 2003.

[36] F. Ahmadinejad, S. Geir Møller, M. Hashemzadeh-Chaleshtori, G. Bidkhori, and M. S. Jami, "Molecular mechanisms behind free radical scavengers function against oxidative stress," Antioxidants, vol. 6, no. 3, pp. 51-66, 2017.

[37] M. I. Rashid, M. I. Fareed, H. Rashid et al., "Flavonoids and their biological secrets," Plant and Human Health, vol. 2, pp. 579-605, 2019.

[38] B. Salehi, E. Azzini, P. Zucca et al., "Plant-derived bioactives and oxidative stress-related disorders: a key trend towards healthy aging and longevity promotion," Applied Sciences, vol. 10, no. 3, p. 947, 2020.

[39] C. M. Snyder, E. H. Shroff, J. Liu, and N. S. Chandel, "Nitric oxide induces cell death by regulating anti-apoptotic BCL-2 family members," PLoS One, vol. 4, no. 9, article e7059, 2009.
[40] U. Wölfle, P. R. Esser, B. Simon-Haarhaus, S. F. Martin, J. Lademann, and C. M. Schempp, "UVB-induced DNA damage, generation of reactive oxygen species, and inflammation are effectively attenuated by the flavonoid luteolin in vitro and in vivo," Free Radical Biology and Medicine, vol. 50, no. 9, pp. 1081-1093, 2011.

[41] M. Shinitzky and Y. Barenholz, "Fluidity parameters of lipid regions determined by fluorescence polarization," Biochimica et Biophysica Acta Reviews on Cancer, vol. 515, no. 4, pp. 367-394, 1978.

[42] R. Veselska and R. Janisch, "The effect of UV irradiation on changes in cytoskeleton and viability of mouse fibroblasts L929 cell line," Scripta Medica, vol. 73, no. 6, pp. 393-408, 2000.

[43] A. Sobiepanek, M. Milner-Krawczyk, K. Bobecka-Wesołowska, and T. Kobiela, "The effect of delphinidin on the mechanical properties of keratinocytes exposed to UVB radiation," Journal of Photochemistry \& Photobiology, B: Biology, vol. 164, pp. 264-270, 2016.

[44] D. Kulms, H. Düssmann, B. Pöppelmann, S. Ständer, A. Schwarz, and T. Schwarz, "Apoptosis induced by disruption of the actin cytoskeleton is mediated via activation of CD95 (Fas/APO-1)," Cell Death \& Differentiation, vol. 9, no. 6, pp. 598-608, 2002.

[45] M. Yoshizumi, T. Nakamura, M. Kato et al., "Release of cytokines/chemokines and cell death in UVB-irradiated human keratinocytes, HaCaT," Cell Biology International, vol. 32, no. 11, pp. 1405-1411, 2008.

[46] M. S. Agren, R. Schnabel, L. H. Christensen, and U. Mirastschijski, "Tumor necrosis factor- $\alpha$-accelerated degradation of type I collagen in human skin is associated with elevated matrix metalloproteinase (MMP)-1 and MMP-3 ex vivo," European Journal of Cell Biology, vol. 94, no. 1, pp. 12-21, 2015.

[47] S. Salucci, S. Burattini, F. Buontempo, A. M. Martelli, E. Falcieri, and M. Battistelli, "Protective effect of different antioxidant agents in UVB-irradiated keratinocytes," European Journal of Histochemistry, vol. 61, no. 3, p. 2784, 2017.

[48] J. Nichols and S. Katiyar, "Skin photoprotection by natural polyphenols: anti-inflammatory, antioxidant and DNA repair mechanisms," Archives of Dermatological Research, vol. 302, no. 2, pp. 71-83, 2010.

[49] E. Markiewicz and O. C. Idowu, "DNA damage in human skin and the capacities of natural compounds to modulate the bystander signalling," Open Biology, vol. 9, no. 12, article 190208, 2019. 